\title{
Pid Controller for Thermal Control in Satellites
}

\author{
Rama Murthy H, Sudharshan Banakar, Pragnyatatti, Mushahira, Gousiya Banu
}

\begin{abstract}
The paper gives the application of PID controller in satellite launching; it gives out the different technique which involves PID controller. It involves the temperature control (thermistor) in heater which is situated in the satellite. PID controller is implemented with the use of programmable logic controller. Using Ordinary control techniques, it is very difficult for controlling temperature; hence the purpose of proposed research is implementing PID controller design using programmable logic controller $(P L C)$ in order to control the temperature and maintain the output in such a way that there is zero error between process variable and set point/desired output by closed loop operations in the satellite by avoiding the manual monitoring system. A thorough analysis using various PID parameters is presented in terms of system response. Performance of the controller is examined in terms of duty cycle, average current and power dissipation. Finally, a comparative analysis of PID controller for thermal control in satellite is presented.
\end{abstract}

Keywords: Temperature, PID, thermistor, MOSFET, duty

\section{INTRODUCTION}

The ultimate aim of carrying this project is to identify the application of PID controller in satellites launching. The discussion also aims to bring out the different technique which involves PID controller. The main apparatus used is the controller. Basically a controller is a device that produces an output signal based on the received input signal. The input signal is actually an error signal, which is the difference between the measured variable and the desired variable. There are various types of controllers. Some of them are as follows:

1. a) on- off controller

1. b) auto tone PID controller

1. c) multi loop controllers

1 .d) safety limit controllers

1. e) temperature switches

\section{PRESENT TECHNIQUES USED IN SATELLITES FOR THE THERMAL CONTROL ARE,}

\subsection{TCS:}

Thermal control system in space craft design, thermal control system functions to keep all the spacecraft

Revised Manuscript Received on July 10, 2019.

Rama Murthy H, Scientist Head Cps, Ur Rao Satellite Center Banglore, Karnataka India. Command Processing Section

Sudharshan Banakar, Asst Proff Dept of ECE, Rao Bahadur Y Mahaballeshwarappa Engineering College, Ballari, Karnataka, India

Pragnyatatti, Student Dept of ECE, Rao Bahadur Y Mahaballeshwarappa Engineering College, Ballari, Karnataka, India

Mushahira, Student Dept of ECE, Rao Bahadur Y Mahaballeshwarappa Engineering College, Ballari, Karnataka, India Gousiya Banu R, Student Dept of ECE, Rao Bahadur Y Mahaballeshwarappa Engineering College, Ballari, Karnataka, India cycle, SCR/microcontroller

components system within acceptable temperature ranges during all the mission phases.
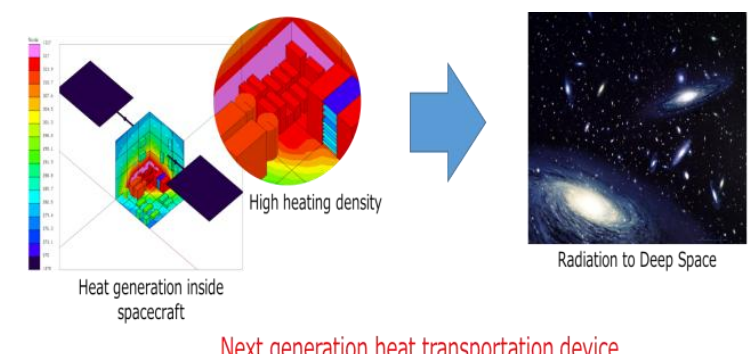

Next generation heat transportation device
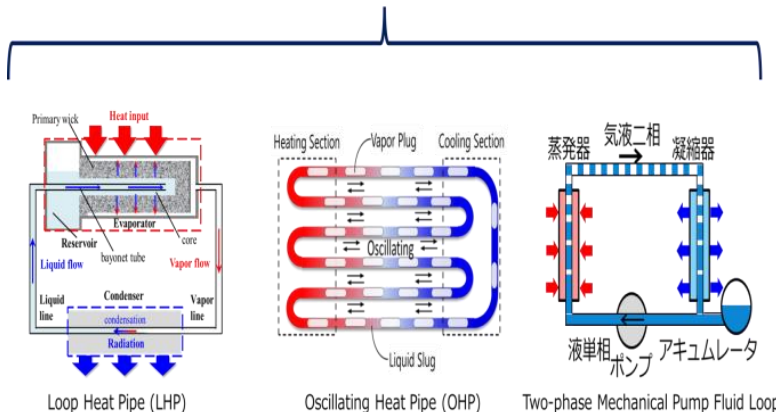

宇宙機におけりる熱閶題と気液二相流熱制御デバイス

Thermal problem for spacecraft and vapor-liquid two-phase thermal control device

Overheating of the equipment is protected by TCS, by either of two ways; which is by thermal insulation or by proper removal of heat from internal components.

\subsection{MLI:}

Multi layer insulator functions to protect the spacecraft from over solar heating as well as from over cooling when exposed to deep space.

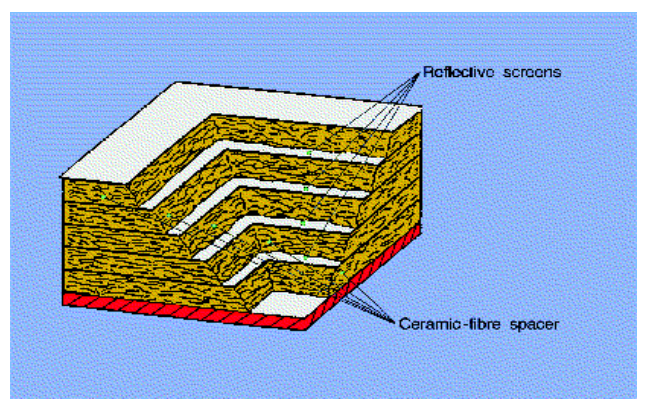

\subsection{HEAT PIPES:}

It is a heat conducting device that unites the principle of thermal conductivity and principle of phase transition to productively transfer heat between two solid interfaces 


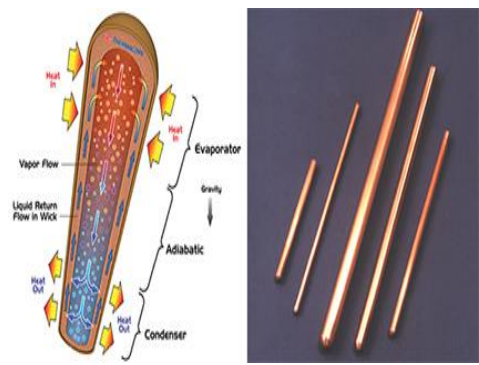

2.4 PTCS AND ATCS-

\section{PTCS:PASSIVE THERMAL CONTROL SYSTEM:}

Components comprise:

$>$ Multi-layer insulation which protects the space craft from abundant solar heating and also from abundant cooling when exposed to deep space.

$>$ Coatings, these change the thermo-optical properties of the external surfaces.

$>$ Thermal washers to reduce the thermal coupling at selected interfaces

$>$ Radioisotope heater units (RHU) which are used by few planetary missions and exploratory missions for producing heat for TCS purposes

\section{ATCS: ACTIVE THERMAL CONTROL SYSTEM}

Components are comprised of:

$>$ Thermostatically controlled resistive electric heaters for keeping the equipment temperature in a cold phase above its lower-limit.

$>$ Fluid loops for transferring the heat that the equipment emits to the radiators. They may be single-phase loops controlled by a pump and 2-phase loops having heat pipes, loop heat pipes, or capillary pumped loops.

\subsection{LOUVERS:}

Which varray the heat rejection potential to space as a function of temperature

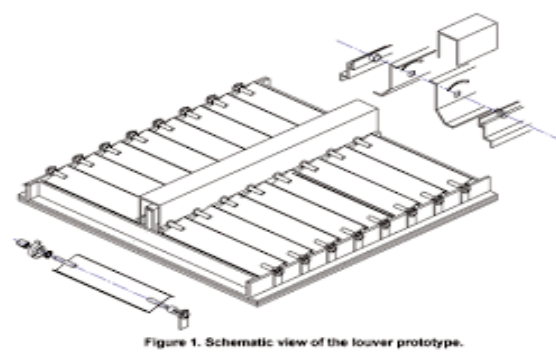

\subsection{HEATERS:}

The most familiar type of heater used in space craft is the patch heater which compose of an electrical resistance element inserted between two sheets of Flexible electrically insulating material such as kapton
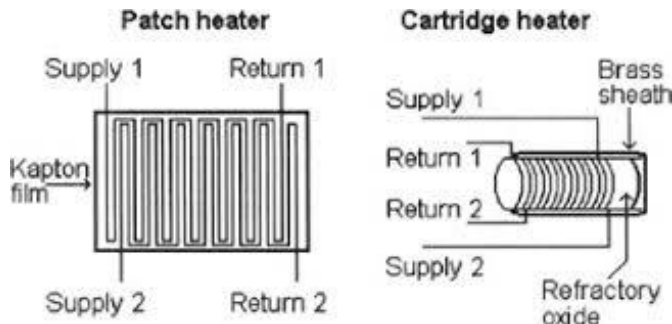

\section{DETAILED DISCRIPTION \& RESULTS}

\subsection{ON-OFF CONTROLLERS}

Thermal balance is very important to all the packages that are maintained at specific temperature. It has active power controllers or active power thermal controllers where different heaters are situated in the spacecrafts which are maintained in different location. Heaters will switch on and switch off by sensing the temperature. Suppose there is a package of sensing elements like thermistors and that thermistor temperature will be read, of course it will be an analog value voltage and it will be converted into digital value by using analog to digital convertor (ADC)

To balance the temperature on-off type controllers are used. this is the present equipment used in the spacecraft by ISRO .this on-off type controller are used in such a way that when the temperature goes below -1 degree Celsius the controller is switched on, in the same way when the temperature increases by +10 degree Celsius the controller is switched off. This information is given by the thermistor so continuously the data is acquired and continuous manual switching on and switching off is accomplished

\subsection{DEMERIT}

This requires continuous monitoring the temperature data and manual switching the heaters is performed which may not be accurate.

\subsection{PID CONTROLLERS}

PID controllers are often called as temperature controllers it takes an input from the temperature sensors (thermistors) and has its own output that is connected to an control element such as heaters or fan.
PID stands for:
P- Proportionality,
I- integration,
D- derivative

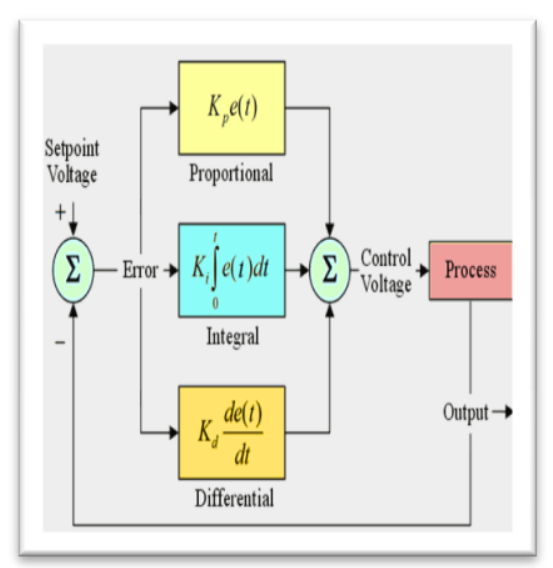

PID uses three basics control behaviours that are explained below

\subsection{P- CONTROLLER}

- This controller gives the output which is proportional to current error e $(\mathrm{t})$. 
- It compares the desired or set point with actual value or feedback process value.

- The resulting error is multiplied with proportional constant to get the output.

- If the error value is zero, then this controller output is zero.

- This controller requires biasing or manual reset when used alone.

- This is because it never reaches the steady state condition.

- It provides stable operation but always maintains the steady state error.

- Speed of the response is increased when the proportional constants $\mathrm{Kc}$ increases.

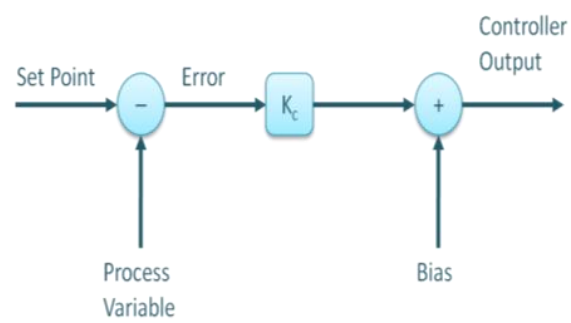

\subsection{I-CONTROLLER}

- Due to constraint of p-controller where there always subsist an offset between the process variable and set point, I- controller is required.

Which provides necessary actions to eliminate the steady state error

- It integrates the error over a period of time until error value reaches to zero.

- It holds the value to final control device at which error becomes zero.

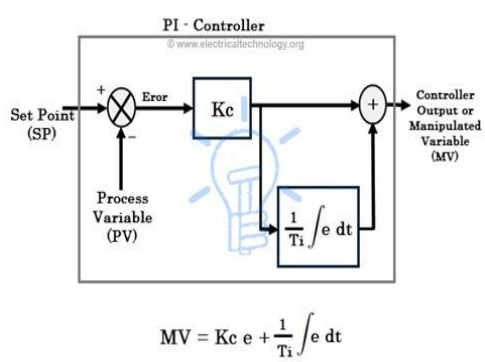

\subsection{D-CONTROLLER}

- The D-controller has the capability to predict the future behavior of the error.

- By anticipating the future behavior of the error.

- Its output depends on rate of change of error with respect to time multiplied by its derivative constant.

- It gives kick start thereby increasing system response.

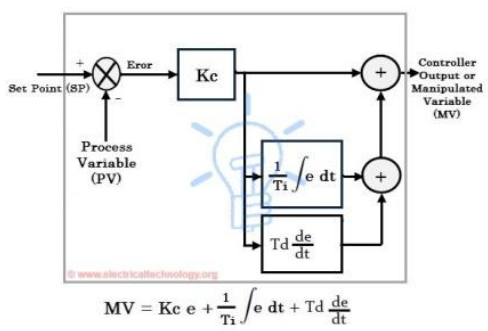

\section{PURPOSE OF PID:}

With the use of on-off controller only two controlled states are possible like fully on or fully off, this on-off type is used for limited control objects. This ON-OFF type controller can be replaced by PID controllers

PID controllers maintain the output in such a way that there is zero error between process variable and set point or desired output by closed loop operations

\section{MAJOR COMPONENTS \& RESULTS}

1. Analog to digital convertors

2. Thermistors

3. Heaters

4. SCR or microcontroller

5. Active and passive type controller

6. MOSFET (enhancement mosfet)

7. PID controller

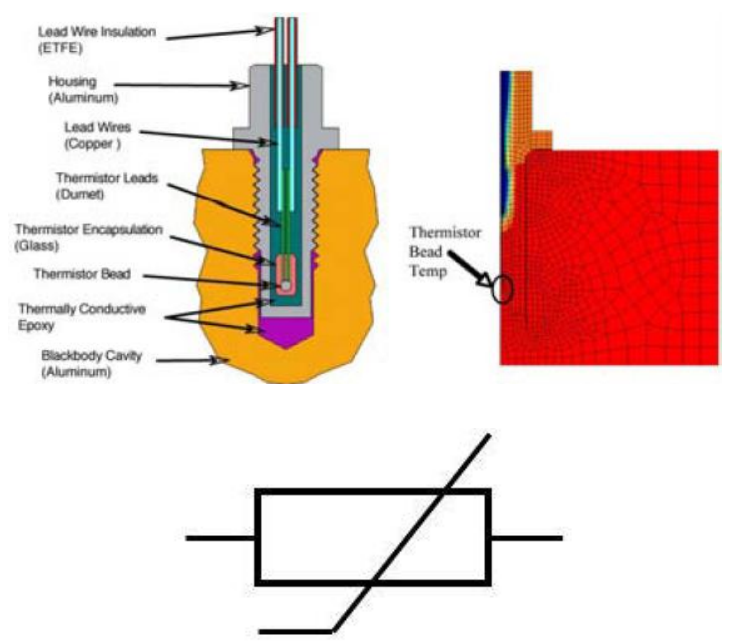

Thermistor symbol

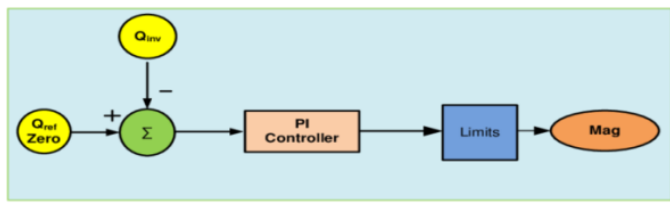

ACTIVE POWER CONTROLLER

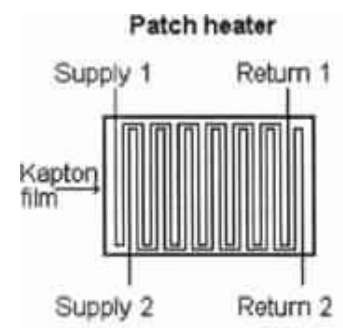

Cartridge heater

Heaters

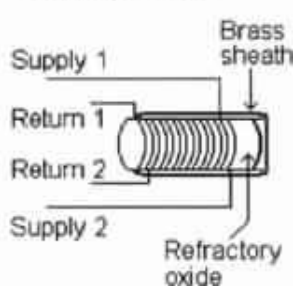

Published By: 


\section{PID CONTROLLER FOR THERMAL CONTROL IN SATELLITES}

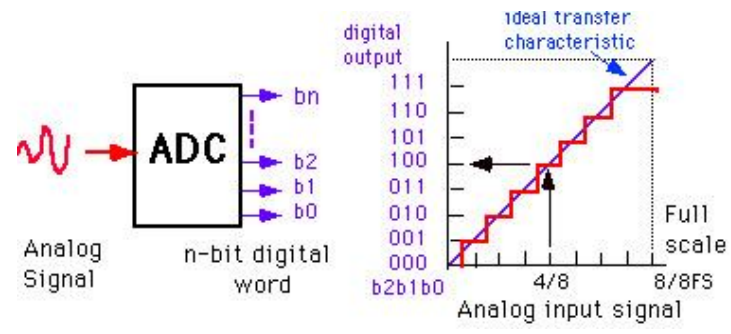

Analog to digital convertors(adc)

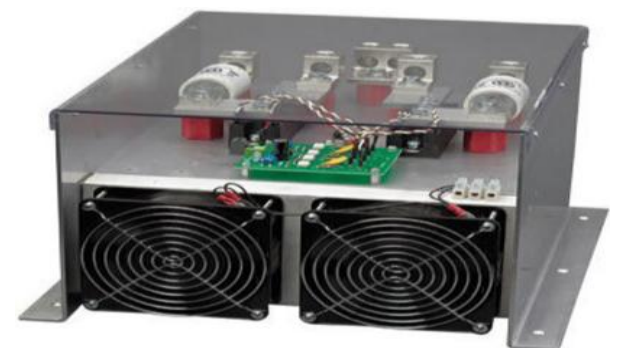

SILICON CONTROLLER RECTIFIER(SCR)
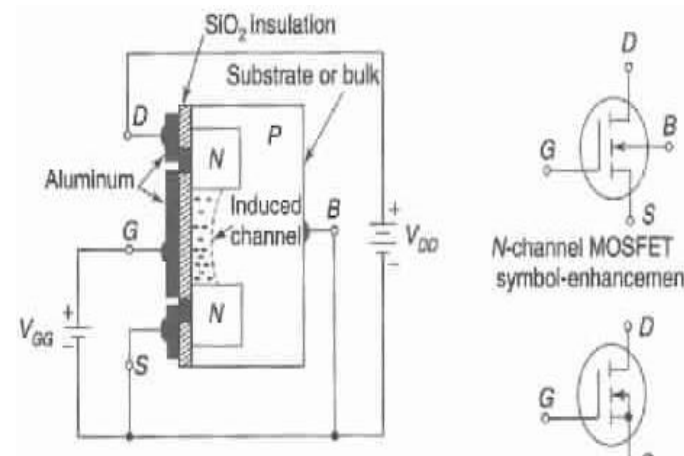

N-channel MOSFET symbol-enhancement type

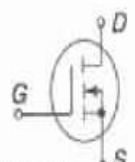

EnhancementMOSFET

\subsection{OPERATION OF PID IN SPACECRAFT}

The operation involve same as that of on-off type controller that is sensing of temperature using thermistor and get the analog value from the thermistor which later is converted into digital value using ADC.

PID controller s differ from on-off type controllers as it has an algorithm that must be applied and it is implemented using SCR(silicon controlled rectifier) or the microcontroller and the code is written to process the data values .

PID controllers use mosfet switches which can be switched to connect the heater load

So that drive to the mosfet is on a duty cycle. If more current is required the mosfet is pumped on for longer time on the other hand the mosfet is pumped for short time to drive low current this is how the duty cycle is varied graphically to check the variations in the control signal.

By changing the duty cycle of control signal the average current can be controlled which will flow from the mosfet and to the load .when the average current is been controlled, the power dissipation of the heater can be controlled.

So basically the work of the algorithm is it will take the temperature value from the thermistor, it will convert along to digital using $\mathrm{ADC}$, having this data value which is sampled continuously takes a set of samples apply the pi algorithm either implement in microcontroller and the duty cycle of the pulse wave in controlling the gate of the mosfet must be derived.
So based on the duty cycle average current that is mosfet conduction time is seen as it is observed in SCR, based on the firing angle the average current through the SCR is controlled .so in this what happens is the average current through the mosfet will be controlled and that will go to the load so this is one technique which can be implemented to thermal control in satellite.

The PID is a continuous control where as heaters are not in heaters what happens is when it is switched on it will be waiting till the upper thermistor comes to switch off the duty cycle of the heater goes like that where as in PID continuously the average current is controlled to maintain the temperature

Suppose if we want the temperature to be maintained at 25 degree Celsius or if we need to hold the temperature that time what happens is we should not allow the heater package to go into higher or lower range, so then it will be controlling continuously.

\subsection{ADVANTAGES}

1. Provide good stability, rapid response and relatively stability

2. Easiest of the continuous controller tunes

3. It fully eliminates the steady state errors i.e. offset

\subsection{DISADVANTAGE}

Sudden variation in set point (error, e) will temporarily cause the derivative term to become very big and thus provides a derivative kick to the elements of final control.

\section{CONCLUSIONS:}

PID controllers work as automated devices timely monitoring of thermal control can be relaxed using PID controllers, in PID continuously the average current is controlled to maintain the temperature whereas it requires personal monitoring in case of $\mathrm{ON}-\mathrm{OFF}$ type controller .

\section{VII.FUTURE WORK}

The PID controller can be widely used in industry, automation system and thermal control areas (power plants)

\section{REFERENCE}

1. HS KALSI for electronic and instrumentation third edition MCGRAW HILL education private limited

2. J.G. Ziegler and N.B. Nichols, "Optimum settings for automatic controllers," Trans. ASME, vol. 64, pp. 759-768, 1942

3. J.G. Ziegler and N.B. Nichols, "Process lags in automatic control circuits," Trans. ASME, vol. 65, pp. 433-444, 1943

4. A.R.J. Ramsey, "The thermostat or heat govemor," Trans. Newcomen Soc., vol. 25, pp. 53-72, 1945- 1947. 